Animal Health Research Institute (Alex. Lab)

\title{
PREVALENCE OF PASTEURELLA MULTOCIDA IN WATERFOWL WHICH SUFFERING FROM RESPIRATORY DISORDER AND ITS SENSITIVITY TO SOME DIFFERENT ANTIBIOTICS
}

(With 6 Tables)

By

\author{
A.A. ABDEL-RAHMAN; A.A. MAHMOUD* \\ and M.E. MAGDY** \\ *Animal Health Research Institute (El- Arish Lab). \\ **Animal Health Research Institute (EL-Minia Lab) \\ (Received at 4/12/2008)
}

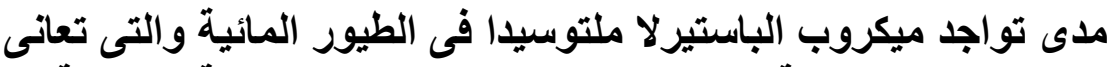

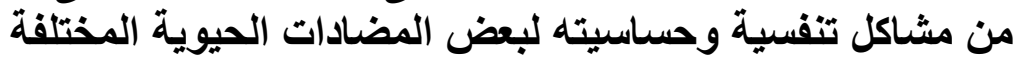

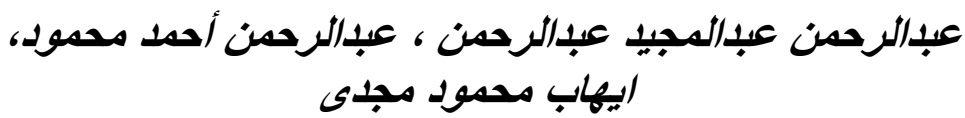

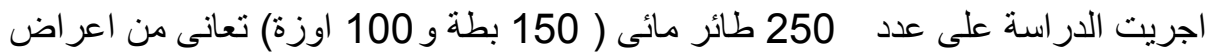

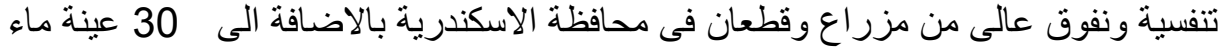

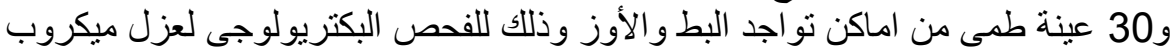

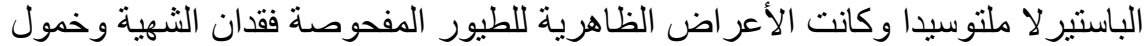

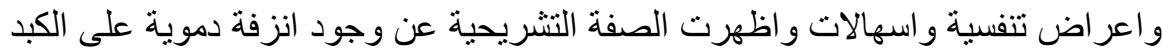

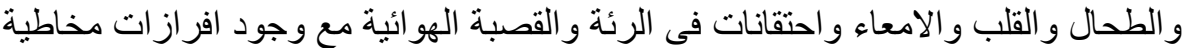

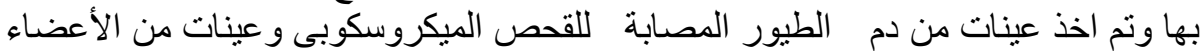

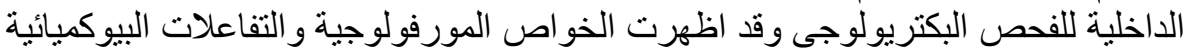

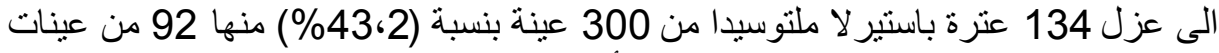

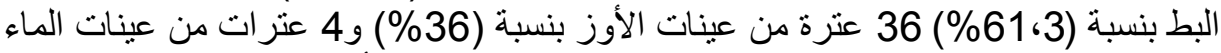

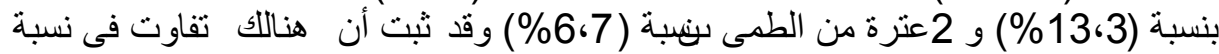

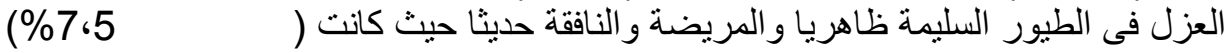

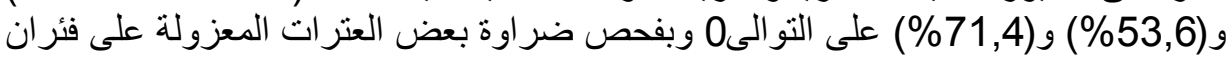

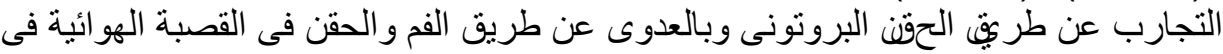

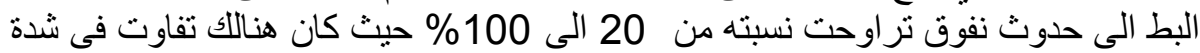

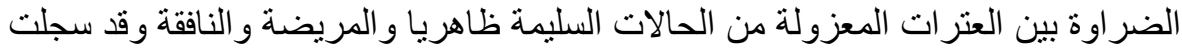

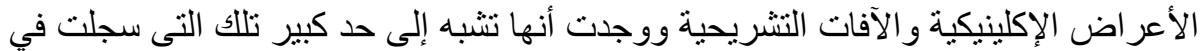

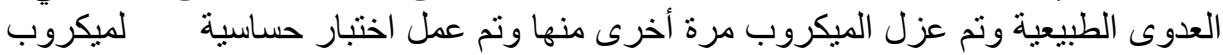

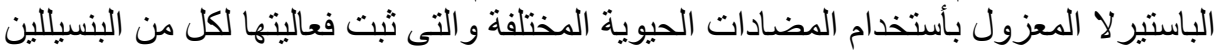

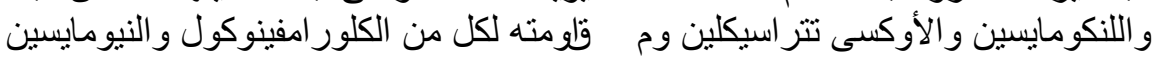




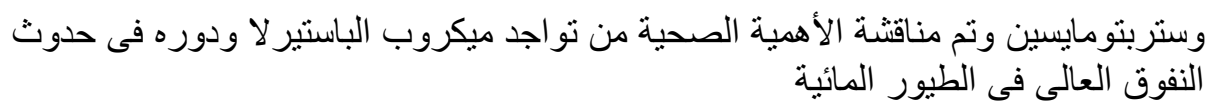

\section{SUMMARY}

A total of 250 waterfowl (150 ducks and 100 geese), having a history of respiratory disorders and mortality, additional to 30 water and 30 sediments samples which waterfowl income were examined in the present study. Samples were collected from different private farms and flock's ducks and geese in Alexandria Province for P.M and bacteriological examination. The clinical sings showed exhausted birds, drowsy, loss of appetite, swim in circles, lameness, swollen wattles, difficult breathing, cyanosis, watery green yellowish diarrhea, ruffled feathers, mucous discharge from the mouth, while postmortem lesions revealed hemorrhages of various sizes on the heart, liver, gizzard and intestines, also white spots and necrotic foci were present on the liver and spleen. Bacteriological examination of these samples for the prevalence of $P$. multocida according to morphological characters and biochemical reactions, revealed 134 P. mulotcida isolates out of 360 samples with incidence of $(43.2 \%)$. $92(61.3 \%)$ of $P$. mulotcida isolates from ducks, $36(36 \%)$ and geese samples, 4 (13.3\%) isolates from water samples and $2(6.7 \%)$ isolates from sediments samples. There are variations in the prevalence rate of $P$. multocida isolates from apparently healthy, diseased and freshly dead in both ducks and geese examined. It was found $3(7.5 \%)$ in apparent healthy, $75(53.6 \%)$ in diseased birds, while was $50(71.4 \%)$ in dead birds. Results of experimental infection of $P$. multocida isolates in mice and ducks revealed difference in mortality rate between strains isolated which ranging from $20 \%$ to $100 \%$ due to difference in the virulence of these strains. The clinical symptoms and post-mortem pictures of experimentally inoculated ducks are similarly to those observed in naturally. Sensitivity test revealed that $P$. multocida isolates were more sensitive to Penicillin, Lincomycin and Oxytetracycline, while were resistant to Chloramephenicol, Neomycin and Streptomycin.

Key words: P. multocida - Fowl cholera, waterfowl, ducks and geese

\section{INTRODUCTION}

Fowl cholera (avian pasteurellosis) is a commonly occurring avian disease that can affect all types of birds and is often fatal (Derieux, 1978). The first outbreak of fowl cholera occurred in a flock of Muscovy 
ducks (Cairina moschata) in Okinawa Prefecture of Japan in November 1990. Fifty (25\%) of 200 birds in a farm died of an acute disease (Nakamine et al. (1992). Also Richard et al. (1967) reported that more than 1,000 geese died in one night suffering from fowl cholera.. Avian cholera has become one of the most important causes of infectious disease causing mortality among North American wildfowl (Stout and Cornwall, 1976; Friend, 1999).

Avian cholera is an infectious disease caused by Pasteurella multocida, a Gram-negative, rod-shaped bacterium, with a bipolar staining characteristic (Rimler and Glisson, 1997).

Pasteurella multocida subspecies multocida is the most common cause of fowl cholera, although $P$. multocida subspecies septica and gallicida may also cause fowl cholera-like disease to some extent Christensen and Bisgaard (2000)

Blanchong et al. (2006) reported that avian cholera, caused by Pasteurella multocida, affects water birds across North America and occurs worldwide among various avian species. Once an epizootic begins, contamination of the wetland environment likely facilitates the transmission of $P$. multocida to susceptible birds

The viability of $P$. multocida has varied with physical and chemical characteristics of water and wetlands. (Bredy and Botzler, 1989 and Price et al., 1992 and Titche, 1979). Wetlands have long been suspected to be an important reservoir for Pasteurella multocida and therefore the likely source of avian cholera outbreaks. P. multocida has been isolated from the water and sediment of wetlands avian cholera epizootics and the bacteria can persist in wetland soil and water (Price and Brand, 1984; Backstrand and Botzler, 1986; Bredy and Botzler, 1989 and Samuel et al., 2003). Also Samuel et al. (2004) isolated P. multocida from 20 of 44 wetlands, including $7 \%$ of the water and $4.5 \%$ of the sediment samples Lehr et al. (2005) studied patterns in avian cholera mortality, the presence of Pasteurella multocida in the water or sediment, and water chemistry characteristics in 10 wetlands. They recovered $P$. multocida from water and sediment samples in six of the 10 study wetlands.

The duck may be a better carrier of $P$. multocida under scavenging system than chickens. This contact cross transmission may be playing a role in the maintenance of the bacterium at the village level (Mbuthia et al., 2005)

\section{Aim of the study}




\section{The aim of the present study:}

1- The incidence of Pasterulla multocida in domestic waterfowl (ducks and geese), water and sediment of wetlands and ponds which waterfowl income

2- Describing the clinical signs and necropsy lesions of Pasterulla multocida infection in ducks and geese

3- Antimicrobial susceptibility of Pasteurella multocida isolates

4- Studying the pathogenicity of $P$. multocida isolates by using experimental animals and birds.

\section{MATERIALS and METHODS}

\section{1- Sources of specimens:}

Samples were collected from different private farms and flock' of ducks and geese in Alexandria Province

\section{2- Collection of samples}

A total of 250 domestic waterfowl included 150 ducks and 100 geese with an average from 4 to 12 months old aged, in additional to 30 water and 30 sediment samples were collected from wetlands and ponds which waterfowl income. Bacteriological examination of water and sediment samples for isolation of $P$. multocida using the methods of (Cruickshank et al., 1982 and Samuel et al. 2003). The healthy status of waterfowl examined were 20 apparently healthy, 90 diseased birds and 40 freshly dead for ducks and 20 apparently healthy, 50 diseased birds and 30 freshly dead for geese. These birds were subjected to postmortem and bacteriological examination for Pateurella multocida investigation. Samples were collected from visceral organs such as lung, liver, spleen, air sacs, intestine, bone marrow, and heart blood of birds. The liver should be removed and placed in a separate bag; Refrigerate these samples as soon as possible after collection and insure that they are kept cool during shipment. Care must be exercised during carcass collection to minimize the amount of fluid discharged into the environment from noses and mouths of diseased birds. Bags of carcasses should always be securely closed before being removed from the area.

\section{3- Isolation and identification of Pasteurella multocida}

Primary isolation by inoculated samples on dextrose starch agar, blood agar, and trypticase-soy agar at $37^{\circ} \mathrm{C}$ for $24-48$ hours. Isolation may be improved by the addition of $5 \%$ heat-inactivated serum. Suspected colonies were examined for their colonial morphology (shape, color and size). A liver impression smear and blood stained with Giemsa and Wright's stain for bipolar rods, through a microscopic examination. 
Identification of $P$. multocida is based on the results of biochemical tests, which include carbohydrate fermentation, enzyme production, and selected metabolite production, were carried out on the isolated strain according to Richard and Glisson (1997) and Glisson (2003). Commercial media and biochemical test kits are available. (Oxoid, 1982).

\section{4- Pathogenicity test of $P$. multocida isolates:}

\section{a) Pathogenicity test of $P$. multocida in vivo in experimental animals:}

The pathogenicity of 3 strains of P.multocida isolated from ducks and geese were used. One strain isolated from each of apparently healthy, diseased birds and freshly dead was used and 20 Swiss mice (46-week-old,) were divided into 4 groups each group contain 5 mice, the last group used as control. One strain for each group was injected into the intraperitoneal of mice, with $5 \mathrm{ml}\left(10^{7} \mathrm{cfu} / \mathrm{ml}\right)$ of $24 \mathrm{hr}$ broth culture. The plate count technique was used for determination of the viable count of cell per $\mathrm{ml}$ of suspension of Pasteurella multocida isolated accordaning (Cruickshank et al., 1982), while last group inoculated by $5 \mathrm{ml}$ sterile normal saline and unlimited foods and water were provided. All inoculated mice were kept under observation, dead mice were recorded and trial for re-isolation of inoculated organisms was conducted.

\section{b) Pathogenicity test of $\boldsymbol{P}$. multocida in experimental birds}

The same isolated previous, three strains of $P$. multocida were used. One strain for each group. Forty-five ducks (3-4 months-old) were obtained from farm and private flock's ducks in Alexandria Province were used in the pathogenicity and experimental studies.

\section{Experimental infection design:}

The experiment was performed to study the pathogenicity of the isolated Pasteurella multocida through oral administration and I/T inoculation by $\left(10^{7} \mathrm{cfu} / \mathrm{ml}\right)$ of $24 \mathrm{hr}$ broth culture of Pasteurella multocida isolate, while control ducks well be gave oral adminstration and I/T inoculation by sterile normal saline., unlimited foods and water are provided. The birds were kept in cages and observed for a period a week. A random samples of five ducks were slaughtered and exposed to post-mortem, parasitological and bacteriological examination, which proved their healthy status and free from diseases, the other birds were classified into 8 groups, each group contain 5 birds., the last group was kept as control. All inoculated ducks were kept under observation for 430 days. Clinical signs and post mortem lesions of dead birds were 
recorded and trial for re-isolation of the inoculated organisms was conducted.

\section{5- In vitro sensitivity of Pasteurella multocida isolates to different antimicrobial agents:}

Antimicrobial susceptibility patterns were carried out using 10 isolates of Pasteurella multocida which isolated from examined samples and 10 chemotherapeutic discs produced by (Oxoid, 1982). The discs included Penicillin (1.5/iu), Ampicillin (10/ug) Lincomycin (15/ug), Ciprofloxacin (10/ug), Chloramphenicol (30/ug), Erythromycin (15/ug), Oxytetracycline (30/ug), Neomycin (30/ug), Gentamycin (10/ug) and Streptomycin (10/ug) One $\mathrm{ml}$ of $24 \mathrm{hr}$. broth cultures was spread on the surface of Mueller-Hinton agar in accordance with the National Committee for Clinical Laboratory Standard (Bergan and Norris,1978). Chemotherapeutic discs were placed on the surface seeded agar. Plates were incubated aerobically at $37^{\circ} \mathrm{C}$ for $24 \mathrm{hr}$. The sensitivity judged according to the diameter of clearance zone around the discs according to Koneman et al. (1988) and Quinn et al. (1994).

\section{RESULTS}

Table 1: Percentage of P. multocida isolated from Waterfowl, water and sediment samples.

\begin{tabular}{|l|c|c|c|}
\hline Source of samples & No of samples & \multicolumn{2}{|c|}{ No. of positive isolates } \\
\cline { 3 - 4 } & & No & $\%$ \\
\hline Waterfowl: & $\underline{250}$ & $\underline{128}$ & $\underline{51.2}$ \\
\hline Ducks & 150 & 36 & 61.3 \\
Geese & 100 & 4 & 13.3 \\
\hline Water & 30 & 2 & 6.7 \\
\hline Sediments & 30 & 134 & 43.2 \\
\hline Total & 310 & & \\
\hline
\end{tabular}

Percentage of P.multocida isolates from examined samples

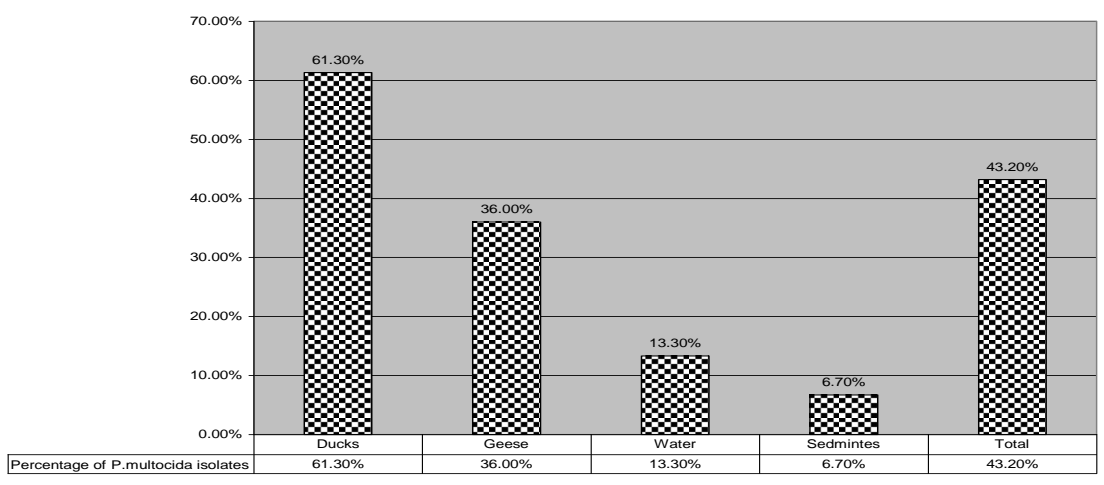


Table 2: Percentage of $P$. multocida isolated from waterfowl, (ducks and geese) according to healthy status.

\begin{tabular}{|c|c|c|c|c|c|c|c|c|}
\hline \multicolumn{9}{|c|}{ Waterfowl } \\
\hline \multirow{3}{*}{ healthy status } & \multicolumn{3}{|c|}{ Ducks } & \multicolumn{3}{|c|}{ geese } & \multirow{2}{*}{\multicolumn{2}{|c|}{$\begin{array}{l}\text { Total No of } \\
\text { P.multocida } \\
\quad \text { isolate }\end{array}$}} \\
\hline & \multirow[t]{2}{*}{$\begin{array}{l}\text { No. of } \\
\text { examine } \\
\text { d birds }\end{array}$} & \multicolumn{2}{|c|}{$\begin{array}{c}\text { No of } \\
\text { P.multocida } \\
\text { isolate }\end{array}$} & \multirow[t]{2}{*}{$\begin{array}{c}\text { No. of } \\
\text { examine } \\
\text { d birds }\end{array}$} & \multicolumn{2}{|c|}{$\begin{array}{l}\text { No of } \\
\text { P.multocida } \\
\text { isolate }\end{array}$} & & \\
\hline & & No. & $\%$ & & No. & $\%$ & No. & $\%$ \\
\hline Apparently healthy & 20 & 2 & 10 & 20 & 1 & 5.0 & 3 & 7.5 \\
\hline Diseased birds & 90 & 60 & 66.7 & 50 & 15 & 30 & 75 & 53.6 \\
\hline Freshly dead birds & 40 & 30 & 75.0 & 30 & 20 & 66.7 & 50 & 71.4 \\
\hline Total & 150 & 92 & 61.3 & 100 & 36 & 36.0 & 128 & 51.2 \\
\hline
\end{tabular}

Percentage of $P$. multocida isolates calculated according to number of healthy statue of each type

Percentage of P.multocida isolates fro ducks and geese

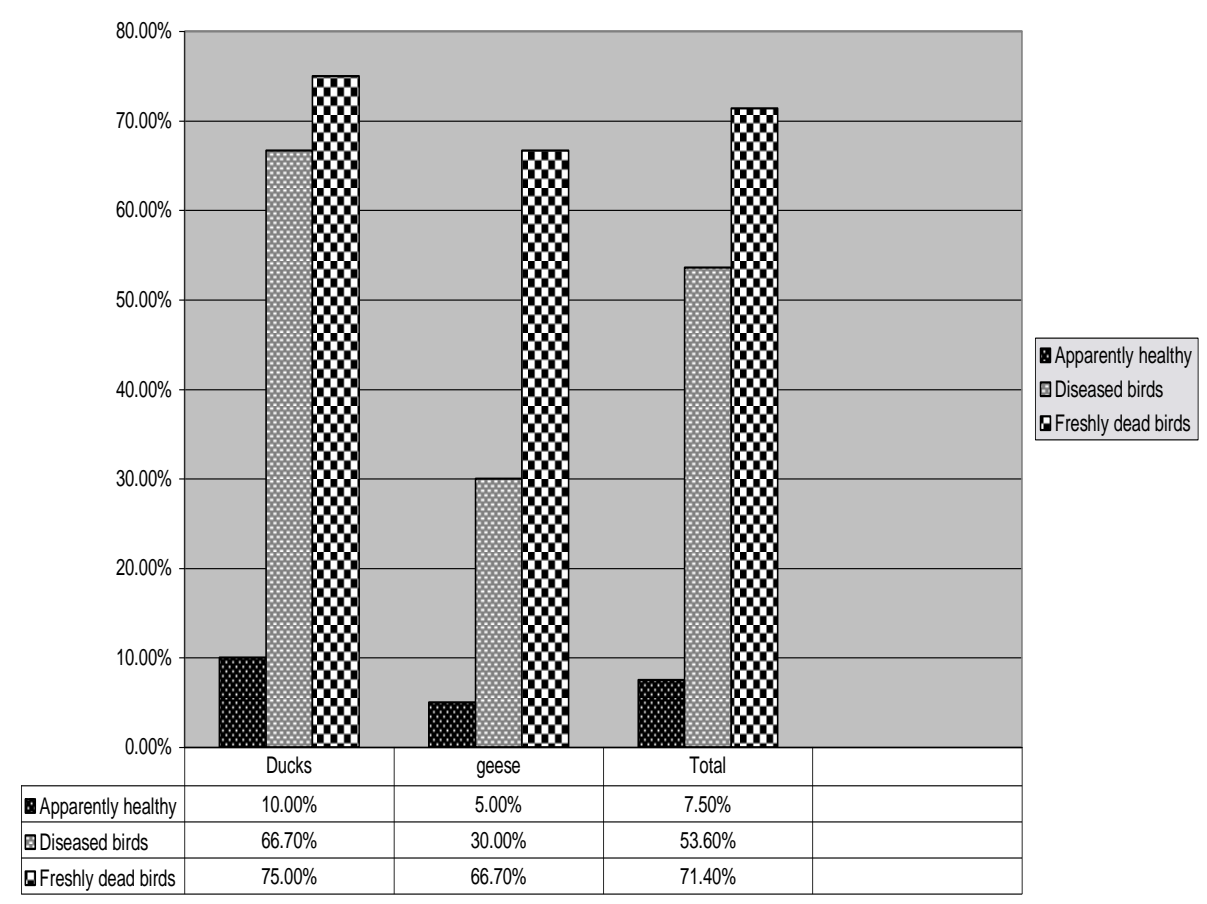


Table 3: Results of biochemical Tests used for identification of Pasteurella multocida

\begin{tabular}{|l|c|}
\hline \multicolumn{1}{|c|}{ Test } & P. multocida \\
\hline Haemolysis on blood agar & - \\
\hline Growth on MacConkey's agar & - \\
\hline Indole production & - \\
\hline Gelatin liquefaction & + \\
\hline Hydrogen sulphide & - \\
\hline Voges-Proskauer & - \\
\hline Methyl red & - \\
\hline Urease production & + \\
\hline Glucose fermentation & - \\
\hline Maltose fermentation & - \\
\hline Lactose fermentation & + \\
\hline Sucrose fermentation & + \\
\hline Ornithine decarboxylase & + \\
\hline Catalase production & + \\
\hline Oxidase production & - \\
\hline Motility & \\
\hline
\end{tabular}

Table 4: Showing the results of pathogenicity of $P$. multocida on Swiss mice

\begin{tabular}{|c|c|c|c|c|c|c|c|}
\hline \multirow{2}{*}{ Groups } & \multirow{2}{*}{$\begin{array}{c}\text { No. of Swiss } \\
\text { mice }\end{array}$} & \multirow{2}{*}{ Source of strain } & \multirow{2}{*}{$\begin{array}{c}\text { Type of } \\
\text { inoculation }\end{array}$} & \multirow{2}{*}{ Rout of infection } & \multirow{2}{*}{$\begin{array}{c}\text { Does of } \\
\text { inoculums }\end{array}$} & \multicolumn{2}{|c|}{ Mortality rate } \\
\hline & & & & & & No. & $\%$ \\
\hline Group (1) & & Apparently healthy & & & & 1 & $20.0 \%$ \\
\hline Group (2) & & Diseased birds & & & & 4 & $80 \%$ \\
\hline Group (3) & 5 & Freshly dead birds & p. multocida & intraperitoneal & $\begin{array}{c}5 \mathrm{ml}\left(10^{7}\right. \\
\mathrm{cfu} / \mathrm{ml})\end{array}$ & 5 & $100 \%$ \\
\hline $\begin{array}{c}\text { Group (4) } \\
\text { control }\end{array}$ & & & Normal saline & & $5 \mathrm{ml}$ & 0 & $0.0 \%$ \\
\hline
\end{tabular}


Table 5: Showing results of pathogenicity of $P$. multocida in ducks

\begin{tabular}{|c|c|c|c|c|c|c|c|c|c|c|c|c|c|c|}
\hline \multirow{2}{*}{$\begin{array}{l}\hat{2} \\
\stackrel{0}{0}\end{array}$} & \multirow{2}{*}{$\begin{array}{l}n \\
0 \\
0 \\
0 \\
4 \\
0 \\
0\end{array}$} & \multirow{2}{*}{ 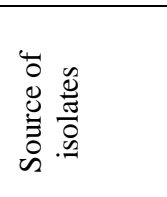 } & \multirow{2}{*}{ 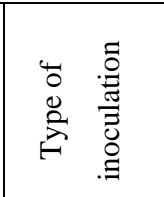 } & \multirow{2}{*}{ 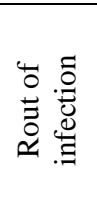 } & \multirow{2}{*}{$\begin{array}{c}\text { Does of } \\
\text { inoculums }\end{array}$} & \multicolumn{6}{|c|}{ Daily deaths post infection } & \multirow{2}{*}{ 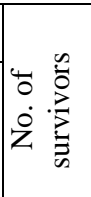 } & \multirow{2}{*}{ 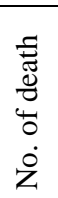 } & \multirow{2}{*}{ 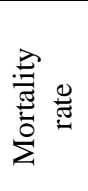 } \\
\hline & & & & & & $1-4$ & $\begin{array}{l}5- \\
15\end{array}$ & $16-20$ & 20 & 25 & $25-30$ & & & \\
\hline \multirow{2}{*}{$\begin{array}{c}\text { Group } \\
1\end{array}$} & 5 & \multirow{2}{*}{$\begin{array}{l}\text { Apparently } \\
\text { healthy }\end{array}$} & \multirow{6}{*}{ p.multocida } & Oral & \multirow{6}{*}{$\left.1 \mathrm{X} 10^{7} \mathrm{cfu} / \mathrm{ml}\right)$} & 0 & 0 & 0 & 0 & 0 & 0 & 5 & 0 & $0.0 \%$ \\
\hline & 5 & & & $\mathrm{I} / \mathrm{T}$ & & 0 & 1 & 0 & 0 & 0 & 0 & 4 & 1 & $20.0 \%$ \\
\hline \multirow{2}{*}{$\begin{array}{c}\text { Group } \\
2\end{array}$} & 5 & \multirow{2}{*}{$\begin{array}{c}\text { Diseased } \\
\text { birds }\end{array}$} & & Oral & & 2 & 1 & 0 & 0 & 0 & 0 & 2 & 3 & $60.0 \%$ \\
\hline & 5 & & & $\mathrm{I} / \mathrm{T}$ & & 3 & 1 & 0 & 0 & 0 & 0 & 1 & 4 & $80.0 \%$ \\
\hline \multirow{2}{*}{$\begin{array}{c}\text { Group } \\
3\end{array}$} & 5 & \multirow{2}{*}{$\begin{array}{c}\text { Freshly } \\
\text { dead birds }\end{array}$} & & Oral & & 4 & 0 & 0 & 0 & 0 & 0 & 1 & 4 & $80.0 \%$ \\
\hline & 5 & & & $\mathrm{I} / \mathrm{T}$ & & 5 & & 0 & 0 & 0 & 0 & 0 & 0 & $100 \%$ \\
\hline \multirow{2}{*}{$\begin{array}{c}\text { Group } \\
4 \\
\text { control }\end{array}$} & 5 & & & Oral & & 0 & 0 & 0 & 0 & 0 & 0 & 0 & 0 & $0.0 \%$ \\
\hline & 5 & & & $\mathrm{I} / \mathrm{T}$ & & 0 & 0 & 0 & 0 & 0 & 0 & 0 & 0 & $0.0 \%$ \\
\hline
\end{tabular}


Table 6: In vitro sensitivity of Pasteurella multocida isolates (No.10) to different antimicrobial agents.

\begin{tabular}{|l|c|c|c|c|c|c|}
\hline \multirow{3}{*}{ Antibacterial agent } & \multicolumn{6}{|c|}{ P. multocida (No.5) } \\
\cline { 2 - 7 } & \multicolumn{2}{|c|}{ Sensitive } & \multicolumn{2}{c|}{ Intermediate } & \multicolumn{2}{c|}{ Resistance } \\
\cline { 2 - 7 } & No & $\%$ & No & $\%$ & No & $\%$ \\
\hline Penicillin (1.5/iu) & 5 & 100 & 0 & 0.0 & 0 & 0.0 \\
\hline Ampicillin (10/ug) & 3 & 60 & 2 & 20 & 0 & 0.0 \\
\hline Lincomycin (15/ug) & 4 & 80 & 0 & 0.0 & 1 & 20 \\
\hline Ciprofloxacin (10/ug) & 3 & 60 & 2 & 40 & 0 & 10 \\
\hline $\begin{array}{l}\text { Chloramephenicol } \\
\text { (30/ug) }\end{array}$ & 0 & 0.0 & 0 & 0.0 & 5 & 100 \\
\hline Erythromycin (15/ug) & 4 & 80 & 1 & 10 & 0 & 0.0 \\
\hline $\begin{array}{l}\text { Oxytetracycline } \\
\text { (30/ug) }\end{array}$ & 4 & 80 & 1 & 20 & 0 & 0.0 \\
\hline Neomycin (30/ug) & 0 & 0.0 & 0 & 0.0 & 5 & 100 \\
\hline Gentamycin (10/ug) & 1 & 20 & 1 & 20 & 3 & 20 \\
\hline Streptomycin (10/ug) & 0 & 0.0 & 1 & 20 & 4 & 80 \\
\hline
\end{tabular}

\section{DISCUSSION}

Pasteurella sp. is normal flora of the respiratory and gastrointestinal tract of many species of domestic and wild birds so it has primary or secondary role in pneumonia of poultry and the virulence of pasteurella is related to the polysaccharide capsule that allow the organism to resist phagocytosis. (Bailey and Scott' s., 1994)

The severity and incidence of P. multocida infections may vary considerably depending on several factors associated with the host including species and age of the infected birds, the environment and the bacterial strain. No single virulence factor has been associated with the observed variation in virulence among strains. (Christensen and Bisgaard, 2000)

Diagnosis depends on isolation and identification of the causative bacterium, Pasteurella multocida. Presumptive diagnosis may be based on the occurrence of typical signs and lesions and/or on the microscopic demonstration of numerous bacteria in blood smears, or impression smears of tissues such as liver or spleen

\section{Clinical signs and gross lesions of the examined ducks and geese showed:}

Sick birds appear exhausted, drowsy, loss of appetite other birds have convulsions, swim in circles, loss of appetite, lameness, swollen and edematous wattles and combs, difficult breathing, cyanosis, watery yellowish or green diarrhea, ruffled feathers, mucous discharge from the 
mouth, Similar Symptoms reported by Friend. (1987), Takahashi et al. (1996) and Woo and Kim (2006) they also showed that similar signs.

The most prominent lesions were hemorrhages of various sizes are found on the heart, liver, gizzard, and intestines. The liver may enlarged and darkened in color; a small number of necrotic and inflammatory foci were also discovered on the liver surface, heart and spleen. The lower portions of the digestive tract commonly contain thickened yellowish fluid, mild ascites and firm material collection in joints. Similar symptoms were recorded by Friend. (1987) and Kwon and Kang (2003) they reported clinical sings of Fowl cholera in all examined birds, including multifocal necrotic foci in the liver with enlargement, petechial hemorrhages on the heart, and mucoid exudates in the duodenal mucosa. Microscopically, there were hepatocytic necrosis with bacterial colonization, hemorrhage and necrosis in the myocardium, and hemorrhagic enteritis. Also Woo and Kim (2006) reported similar symptoms included orofacial edema, wattle and comb swelling, and respiratory symptoms. The cardiac air sac was filled with inflammatory materials, and serious pneumonic lesions were also found at the end of the lung lobe

Microscopical examination of blood samples and tissue smears of organs revealed bipolar staining bacillus and the pure colonies on blood agar plates showed transparent, glossy, and big colonies gave off a characteristic and sweet smell, Colonies range from 1 to $3 \mathrm{~mm}$ in diameter after 18-24 hours of incubation and are discrete, circular, convex, translucent which is characteristic of $P$. multocida. Results of biochemical test of pure isolate illustrated on Table (3). These results agree with those reported by (Bisgaard et al., 1991; Murray et al., 1995; and Woo and Kim, 2006). They identification of Pasteurella species included Gram staining, motility test, glucose fermentation test, oxidase and catalase reactions. The strains obtained were typed by using the following reactions; ornithine decarboxylation, urease production, indole formation and production of acid from sucrose, maltose, mannitol, dulcitol, and sorbitol.

Bacteriological examination of samples according to the morphological characters, biochemical reactions of the recovered Pasteurella multocida were Tabulated in Table (1) revealed 134 (43.2\%) out of 310 samples were positive to $P$. multocida. The positive samples included, $128(51.2 \%)$ out of 250 waterfowl, 4 (13.3\%) out of 30 water samples and $2(6.7 \%)$ out of 30 Sediment samples. 
Wetlands have long been suspected to be an important reservoir for Pasteurella multocida and therefore the likely source of avian cholera outbreaks $P$. multocida has been isolated from the water and sediment of wetlands experience avian cholera epizootics and the bacteria can persist in wetland soil and water (Price and Brand 1984; Backstrand and Botzler, 1986)

The incidence of $P$. multocida in both water and Sediments samples in our study were $(13.3 \%)$ and $(6.7 \%)$ respectively. These results are higher than that obtained by Samuel et al. (2004) They attempted to isolate $P$. multocida from 440 water and 440 sediment samples collected from 10 wetlands during winter and spring seasons. They could not be isolate $P$. multocida from envy samples. In contrast, they could isolated P. multocida from 20 of 44 wetlands, including $7 \%$ of the water and $4.5 \%$ of the sediment samples on the other side Lehr et al. (2005) could not be isolated P. multocida from 786 water and 786 sediment samples during winter 1997, while during winter 1998 could be isolated P. multocida serotype 1 from three enzootic and three reference wetlands at percentage of 14 out of $396(3.5 \%)$ water samples and one out of $396(0.3 \%)$ sediment samples .

Table (2) revealed 128 P. multocida isolates from all waterfowl samples (ducks and geese) with allover incidence of $(51.2 \%)$. Out of these $92(61.2 \%)$ from ducks and 36 (36\%) from geese examined samples. We could be isolated $P$. mulotcida from apparent healthy, diseased, and freshly dead ducks at percentages of (10.0\%). (66.7\%) and (75.0\%) respectively while from geese were $(5.0 \%),(30.0 \%)$ and $(66.7)$ respectively.

Our results are higher than that obtained by Nakamine et al. (1992) they isolated Pasteurella multocida from Fifty (25\%) of 200 Muscovy ducks during outbreak of fowl cholera in Okinawa Prefecture of Japan, Samuel et al. (1997) isolated P. multocida serotype 1 from an adult male goose and $P$. multocida serotype 3 from an adult female goose out of 298 lesser snow geese and also higher than recorded by (Muhairwa et al., 1999) they detected of P. multocida in ducks at percentage of $(7 \%)$ in all three zones investigated, Mbuthia et al. (2007) they could be isolated $P$. multocida from only four chickens out of 123 birds examined, while could not be isolated from 24 ducks examined on the basis of biochemical characterization. Samuel et al., (2003) could be isolated P. multocida from apparently healthy geese. Also Lehr et al. (2005) found that a small proportion of 322 wild birds $(<5 \%)$ were carriers of pathogenic P. multocida. On the basis of serology, an 
additional group of these birds $(<10 \%)$ were survivors of recent avian cholera infection. They also found these birds were carriers of $\mathrm{P}$. multocida even in the absence of disease outbreaks while, our results are lower than that obtained by Takahashi et al. (1996) they isolated Nine strains of Pasteurella multocida from Muscovy ducks, 5 to 6 dead ducks at percentage of $(83.3 \%)$ and 4 of 8 ducks with percentage of (50.0\%) from ducks have clinical of subacute disease characterized by lameness, corneal turbidity, and depression, and Leotta et al. (2006) they could be isolated Fifty-five $P$. multocida gallicida, type A:1 from Eighty-six dead birds and one from water samples

\section{Pathogenicity in vivo on mice}

Results for the virulence of 3 strains of P. multocida on 3 groups of mice (each group contain 5 mice) within 24-48 hours after inoculation, recorded $20 \%$ mortality. by strain isolated from apparent healthy, $80 \%$ mortality with strain isolated from diseased birds and $100 \%$ with strain isolated from freshly dead birds, while no death from control group Table (4).

From direct smear, specimens of heart blood from dead mice were observed through the microscopic examination, bipolar staining bacillus were observed in all the specimens. This shows that there is a difference in mortality rate between strains isolated from examined ducks and geese due to difference in virulence of the strains.

\section{Pathogenicity in ducks:}

Results of experimental infection of the susceptible ducks, instullated in Table (5) that the $P$. mulotcida isolates were pathogenic on experimental ducks through oral administration and I/T inoculation with a variety of mortality rates. It showed that, the first group which inoculated with strain isolated from apparent healthy cases was revealed 0 to $20 \%$ mortality, and the second group which, inoculated with strain isolated from diseased birds was ranged from 60 to $80 \%$, while was 80 to $100 \%$ in the third group which inoculated with strain isolated from freshly dead birds, while no death recorded in control group.

The clinical symptoms, direct smear of heart blood from dead birds revealed gram-negative, bipolar staining bacillus and post-mortem pictures of dead birds, are similarly that showing in examined ducks and geese samples in our work and agree with those reported by the author Samuel et al. (2003) they found that virulence of P. multocida isolates from wetlands and Pekin ducks, ranged from (0 to 100\%). In contrast, the virulence of isolates collected during the winter of 1997 from other wetlands ranged from (67\% to $100 \%)$ and agree with reported those by 
Wobeser (1997) who reported that virulence among strains within the same P. multocida serotype may be different. Samuel et al. (1997) reported that pathogenicity of the serotype 1 isolate was confirmed by inoculation in Pekin ducks (Anas platyrhynchos). while; serotype 3 isolate was non-pathogenic in Pekin ducks and could be isolated from pathogenic $P$. multocida serotype 1 from apparently healthy wild snow geese.

\section{Antimicrobial drugs susceptibility}

The extensive use of antibiotics as growth promoters and prophylactic agents for disease control in veterinary medicine has undoubtedly been responsible for large numbers of bacteria that have become resistant to different antibiotics. In-vitro tests the proper antimicrobial agents against $P$. multocida isolates, illustrated in Table (6) five strains were tested against 10 antimicrobial drugs. These strains somehow acquired a significantly high level of resistance to 3 types of antimicrobial drugs: Chloramephenicol (100\%), Neomycin (100\%) and Streptomycin (80\%), while highly sensitive to 4 types of antimicrobial drugs which included, Penicillin (100\%), Lincomycin (80\%), Oxytetracycline (80\%) and Ampicillin (80\%). Some of these results are agreed with those obtained by (Morishita et al., 1996) they reported that P. multocida isolates were susceptible to Penicillin G, Sulfisoxazole, Tetracycline, and Trimethoprim-sulfamethoxazole. While, Woo and Kim (2006) they found that P. multocida was of high level of resistance to 7 types of antimicrobial drugs: Kanamycin, Neomycin, Oxytetracycline, Tetracycline, Tobramycin, Doxycycline, and even Gentamicin.

\section{Conclusion:}

From the abovementioned results, it can be concluded that a variation in virulence and survival of $P$. multocida might explain why avian cholera outbreaks were observed without detecting pasteurellae in the environment. Virulence among strains within the same $P$. multocida serotype may vary.

Strict control on entry of feed bags, equipment and personnel is necessary to exclude infection with fowl cholera. As well as, rodents need to be controlled and free-flying birds excluded. Carcass collection to reduce bacterial contamination in wetlands is the current method used to control avian cholera in waterfowl. Other tools to control avian cholera have been suggested, including treatment of water chemistry to reduce the survival of $P$. multocida (Friend, 1999). 


\section{REFERENCES}

Backstrand, J.M. and Botzler, R.G. (1986): Survival of Pasteurella multocida in soil and water in an area where avian cholera is enzootic. Journal of Wildlife Diseases 22: 257-259

Bailey and Scott S. (1994): Genus pasteurella In: Diagnostic Microbiology $9^{\text {th }}$ Edition P. 420-422 (part4)

Bergan, T. and Norris, J.R. (1978): Pasteurella multocida, Biochemical characteristics and serotypes, p.271-292. In Methods in microbiology, volume 10, Academic press, New York.

Bisgaard, M.; Houghton, S.B.; Mutters, R. and Stenzel, A. (1991): "Reclassification of German, British and Dutch isolates socalled Pasteurella multocida obtained from pneumonic calf lungs", Veterinary Microbiology, 26,

Blanchong, J.A.; Samuel, M.D.; Goldberg, D.R.; Shadduck, D.J. and Lehr, M.A. (2006): Persistence of Pasteurella multocida in wetlands following avian cholera outbreaks J. Wildl Dis.; 42(1):33-9

Bredy, J.P. and Botzier, R.G. (1989): The effects of six environmental variables on Pasteurella multocida populations in water. Journal of Wildlife Diseases 25: 232-239

Christensen, J.P. and Bisgaard, M. (2000): Fowl choleraRev Sci Tech.; 19(2):626-37.

Cruickshank, R.; Duguid, J.P.; Marmoni, B.P. and Swain, R.H. (1982): Medical Microbiology. $12^{\text {th }}$ Ed., Churonill Livingestone Edinburg, London, UK

Derieux, W.T. (1978): Response of young chickens and turkeys to virulent and a virulent Pasteurella multocida administered by various route. Avian Diseases 22, 131-139

Friend, M. (1987): Field guide to wildlife diseases.U.S. Fish Wildl. Serv., Resour. Publ. 167. 225 pp.

Friend, M. (1999): Avian cholera. In Field manual of wildlife diseases: General Field procedures and diseases of birds, M. Friend and J. C. Franson (Eds.). Information and Technology Report 1999001, Biological Resource Division, U.S. Geological Survey, Madison, Wisconsin, pp. 75-92.

Glison, J.R. (2003): "Pasteurella and other related bacterial infection" In: Diseases of poultry edited by Saif, Y.M.Barnes.H.J.; Glison, J.R; Fadly, A.M.; McDougald, L.R. and Swayne, D.E. p.661 $11^{\mathrm{TH}} \mathrm{Ed}$. 
Koneman, E.; Allen, S.; Damsel, ver and Somme, S.H. (1988): "Colour Atlas and text book of Diagnostic Microbiology 2NDJ.B Lip. Co. London.

Kwon, Y.K. and Kang, M.I. (2003): Outbreak of Fowl Cholera in Baikal Teals in Korea Avian Diseases, Vol. 47, No. 4, pp. 1491-1495.

Lehr, M.A.; Botzler, R.G.; Samuel, M.D.; Shadduck, D.J. (2005): Associations between water quality, Pasteurella multocida, and avian cholera at Sacramento National Wildlife Refuge. J. Wildl Dis.; 41(2): 291-7.

Leotta, G.A.; Chinen, I.; Vigo, G.B.; Pecoraro, M. and Rivas, M. (2006): Outbreaks of avian cholera in Hope Bay, Antarctica J Wildl Dis.; 42(2): 259-70

Mbuthia, P.G.; Njagi, L.W.; Nyaga, P.N.; Bebora, L.C.; Minga, U.M. and Mugera, G.M. (2005): Indigenous Ducks are Better Reservoirs of $P$. multocida than Indigenous Chickens Kenya Veterinarian Vol. 29 pp. 104-106

Mbuthia, P.G.; Njagi, L.W.; Bebora, L.C.; Mugera, G.M.; Ngatia, T.A.; Munyua, W.K.; Nyaga, P.N.; Minga, U. and Olsen, J.E. (2007): Preliminary Findings on the Carrier Status of Pasteurella multocida in Farmed and Traded Healthyappearing Scavenging Indigenous Chickens and Ducks in Kenya Kenya Veterinarian > Vol. 31, No. 1 (2007)

Morishita, T.Y.; Lowenstine, L.J.; Hirsh, D.C. and Brooks, D.L. (1996): Pasteurella multocida in raptors: prevalence and characterization. Avian Dis.; 40(4): 908-18.

Muhairwa, A.P.; Mtambo, M.M.A.; Christensen, J.P. and Bisgaard, M. (1999): "Occurrence of Pasteurella multocida and related species in village scavenging poultry and animals that are kept in contact" (Submitted for publication).

Murray, P.R.; Baron, E.J. and Pfaller, M.A. (1995): Manual of clinical microbiology, 6th ed., p.505-506, American Society of Microbiology press, Washington, D.C.

Nakamine, M.; Ohshiro, M.; Ameku, Y.; Ohshiro, K.; Keruma, T.; Sawada, T. and Ezaki, T. (1992): The first outbreak of fowl cholera in Muscovy ducks (Cairina moschata) in Japan J. Vet. Med Sci.; 54(6):1225-7

Oxoid Manual (1982): The Oxoid manual of culture media, ingredients and other laboratory services $5^{\text {th }}$ Ed. Oxoid Limit 
Price, J.I. and Brand, C.J. (1984): Persistence of Pasteurella multocida in Nebraska wetlands under epizootic conditions. Journal of Wildlife Diseases 20: 90-94

Price, J.I.; LYandell, B.S. and Portter, W.P. (1992): Chemical ions affect survival of avian cholera organisms in pond water. The Journal of Wildlife Management 56: 274-278.

Quinn, P.J.; Carter, M.E.; Makey, B. and Carter, G.R. (1994): Clinical Veterinary Microbiology Wolf Publishing an imprint of Mosby-year book Europe Limited, Lynton House, 7-10 Tavistock Spuare, London.WC IH9LB, England

Richard, R.B. and Glisson, J.R. (1997): Fowl cholera" In Diseases of poultry Edited by Calnek, B.W.. John, H. Barnes, Beard C.W. Medougald, L.R. and Saif, Y.M. p 143-159 $10^{\text {th }}$ Ed.

Richard, W.V.; Harold, C.M. and Harold, H.B. (1967): Fowl Cholera in waterfowl at squaw creek National Wildife Refuge, Missour. The Journal of Wildlife Management, Vol. 31, No. 2 pp.248253.

Rimler, R.B. and Glisson, J.R. (1997): Fowl cholera. In Diseases of poultry, 10th Edition. B. W. Calnek, H. J. Barnes, C. W. Beard, L. R. Mc- Dougald, and Y. M. Saif (eds.). The Iowa State University Press, Ames, Iowa, pp. 143-159.

Samuel, M.D.; Shadduck, D.J. and Goldberg, D.R. (2004): Are wetlands the reservoir for avian cholera? J. Wildl Dis.; 40(3): 377-82

Samuel, M.D.; Shadduck, D.J.; Goldberg, D.R.; Wilson, M.A.; Joly, D.O. and Lehr, M.A. (2003): Characterization of Pasteurella multocida isolated from wetland ecosystems during 1996 to 1999. Journal of Wildlife Diseases 39: 798-807

Samuel, M.D. Goldberg, D.R.; Shadduck, D.J.; Price, J.I. and Cooch, E.G. (1997): Pasteurella multocida serotype 1 isolated from a lesser snow goose: Evidence of a carrier state. Journal of Wildlife Diseases 33: 332-335.

Stout, I.J. and Cornwall, G.W. (1976): Non-hunting mortality of fledged North American waterfowl. The Journal of Wildlife Management 40: 681-693.

Takahashi, S.; Sato, H.; Yamada, T.; Takenouchi, T.; Sawada, T.; Nakano, K. and Saito, H. (1996): Outbreaks of fowl cholera in Muscovy ducks (Cairina moschata) on a farm in Aomori Prefecture J. Vet. Med. Sci.; 58(3):269-72 
Titche, A. (1979): Avian cholera in California. Wildlife Management Branch Administrative Report 79-2. California Department of Fish and Game, Sacramento, California, $49 \mathrm{pp}$

Wobeser, G.A. (1997): Diseases of wild waterfowl. Plenum Press, New York, New York, pp. 57-69

Woo, Y-Ku and Kim, J.H. (2006): Fowl Cholera Outbreak in Domestic Poultry and Epidemiological Properties of Pasteurella multocida Isolate the Journal of Microbiology, p. 344-353 